\title{
Role of Nutraceuticals in Neurodegenerative Diseases
}

\author{
Anitha Nandagopal ${ }^{1 *}$, Kulsum Siddiqui ${ }^{1}$ \\ 1 Department of Pharmacology, Sultan-ul-Uloom College of Pharmacy, Road No: 3, Banjara Hills, Hyderabad-500034, \\ Telangana State, India.
}

\begin{abstract}
Nutraceuticals are food-derived compounds considered beneficial for human health. It has been recently shown that nutraceuticals play an important role in the regulation of brain physiology and in the prevention of neurodegeneration and cognitive decline. Nutraceuticals differ structurally and therefore act at different biochemical and metabolic levels and have shown different types of neuroprotective properties which include mitochondrial dysfunction, intracellular calcium overload, oxidative stress and inflammation. Nutraceuticals have recently gained importance owing to their multifaceted effects. These food-based approaches are believed to target at multiple pathways in a slow but more physiological manner without causing severe adverse effects.
\end{abstract}

Keywords: Nutraceuticals, neurodegeneration, mitochondria, calcium, oxidative stress.

\section{INTRODUCTION}

Neurodegenerative disease indicates a range of conditions which primarily affect the neurons. Neurons are building blocks of the nervous system and don't reproduce or replace themselves. Neurodegenerative diseases are characterized by progressive degeneration or death of the neurons. Neurodegenerative diseases occur as a result of damage to the neurons. These diseases are associated with mutated genes, accumulation of abnormal proteins, increased reactive oxygen species or destruction of neurons in specific part of brain.

*Corresponding Author: Anitha Nandagopal, e-mail: anirajan_76@yahoo.co.in Anitha Nandagopal ORCID Number: https://orcid.org/0000-0002-4294-9412 Kulsum Siddiqui ORCID Number: https://orcid.org/0000-0002-7332-7704 (Received 13 May 2019, accepted 12 August 2019) 


\section{TYPES OF NEURODEGENERATIVE DISEASES}

There are four types of neurodegenerative diseases which are shown in Figure 1.

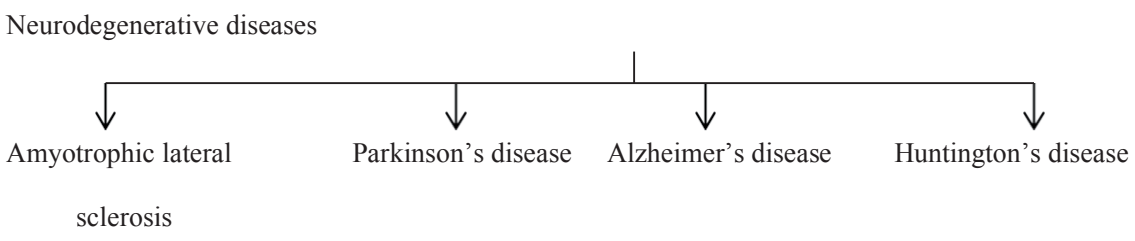

Figure. 1 Types of neurodegenerative diseases.

\section{Amyotrophic lateral sclerosis (ALS)}

ALS is a disease of motor neurons of the anterior horns of spinal cord and motor neurons in the cerebral cortex. It is a specific disease which causes the death of neurons controlling voluntary muscles. It is characterized by stiff muscles and muscles twitching. It begins with weakness in the arms or legs or with difficulty in speaking or swallowing ${ }^{1}$. Excitotoxicity mediated by glutamate and elevated calcium ion is considered to be a major mechanism of neuronal death in ALS $^{2}$.

\section{Parkinson's disease (PD)}

It is an extrapyramidal motor disorder characterized by rigidity, tremor and hypokinesia with secondary manifestations like defective posture and gait, mask like face and sialorrhoea ${ }^{3}$.

It is characterized by,

- Degeneration of dopaminergic neurons that produces dopamine in basal ganglia.

- An imbalance between acetylcholine and dopamine in brain.

- Formation of lewy bodies.

- Loss of dopamine results in akinesia, rigidity and bradykinesia.

- Excess amount of acetyl choline result in tremor and sialorrhoea.

\section{Alzheimer's disease (AD)}

$\mathrm{AD}$ is a neurological brain disorder which is the most common form of dementia and it is a group of disorders which impairs mental functioning ${ }^{4}$. It is progressive and irreversible. Memory loss is the earliest symptoms, along with gradual decline of other intellectual and thinking abilities, called cognitive functions and changes in personality or behavior. 
It is characterized by,

- Decrease in acetylcholine levels in cerebral cortex and hippocampus which results in progressive and significant loss of cognitive and behavioral function.

- Deposition of amyloid plaques and neurofibrillary tangles.

- Microglial and astroglial activation which finally leads to neuronal dysfunction and death.

\section{Huntington's disease (HD)}

HD is an inherited disease which results in death of the brain cells. As the disease advances, uncoordinated and jerky body moment become more apparent $^{5}$. Physical abilities gradually worsen until coordinated movement become difficult and the person is unable to talk ${ }^{6}$. Mental abilities generally decline into dementia. The disease is caused by autosomal dominant mutation of a gene called huntingtin ${ }^{7}$.

\section{MECHANISM OF NEURONAL DAMAGE}

There are several mechanisms recognized which leads to neurotoxicity as shown in Figure 2.

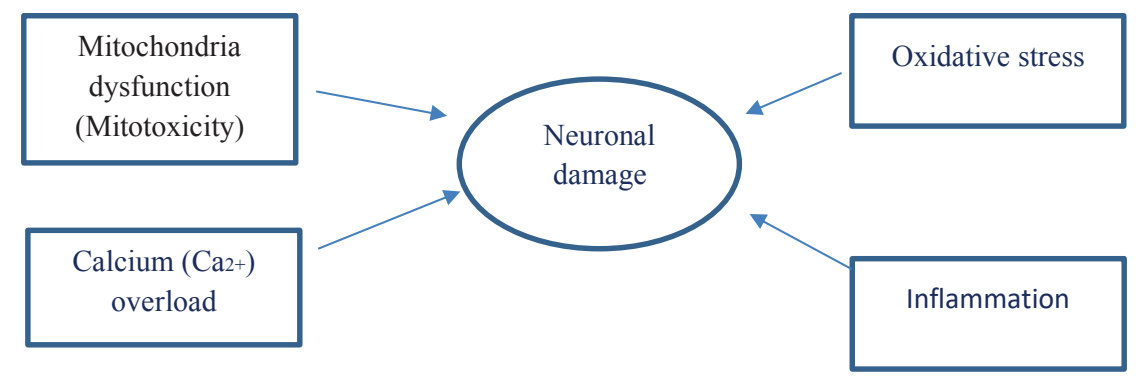

Figure. 2 Mechanism of neurotoxicity Mitotoxicity mediated neuronal damage

\section{Mitotoxicity mediated neuronal damage}

Pathophysiology of neurodegenerative diseases such as AD, ALS, PD and HD involves damage to mitochondria ${ }^{8}$. Mitochondrial function is under the control of two genomes i.e. nuclear DNA (nDNA) and mitochondrial DNA (mtDNA). Mutation in either of these genomes can result in mitotoxicity-mediated neurodegeneration ${ }^{9}$.

The neurotoxicant, 1 methyl-4-phenylpyridium(MPP+), generated from the mono amine oxidase MAO)- catalyzed oxidation of 1-methyl-4-phenyl-1,2,3,6- 
tetrahydropyridine (MPTP) within the brain which is concentrated inside the mitochondria of dopaminergic cells and inhibits complex I of the respiratory electron transport chain (ETC), which leads to the development of $\mathrm{PD}^{10}$.

Mutant huntingtin, the gene which is responsible for the development of HD, directly impair mitochondrial functions ${ }^{11}$. Defective mitochondrial complex I, II, III and IV were found in the postmortem tissue of HD patients ${ }^{12}$. Mitochondrial abnormalities also result in the neuronal damage in AD and ALS.

\section{Calcium overload-mediated neuronal damage}

In general, calcium in extracellular space remains in milli molar range, while inside the cell it remains in micro molar range ${ }^{13}$. Maintenance of intracellular $\mathrm{Ca}^{2+}$ is very important for the survival of neuronal cells. If there is a sudden rise in intracellular $\mathrm{Ca}^{2+}$, it triggers a cascade of neurotoxic events, including mitotoxicity and cessation of ATP synthesis, over activation of several $\mathrm{Ca}^{2+}$ dependent hydrolytic enzymes such as proteases, phospholipases, nucleases, nitric oxide synthase and phosphatases. These events lead to the onset of neurotoxicity, impaired neuronal functions and eventually death of the neuronal cells.

Accumulation of $\mathrm{Ca}^{2+}$ in neuronal cells occur through several routes such as activation of voltage-sensitive $\mathrm{Ca}^{2+}$ channel, receptor operated $\mathrm{Ca}^{2+}$ channel (N-Methyl-D-Aspartate (NMDA)), ATP-dependent $\mathrm{Ca}^{2+}$ channel, cyclic nucleotide-gated $\mathrm{Ca}^{2+}$ channel, $\mathrm{Ca}^{2+}$ channel coupled to $\mathrm{G}$ protein receptors. Plasma membrane, endoplasmic reticulum and mitochondria can only handle rise in intracellular $\mathrm{Ca}^{2+}$ up to a certain extent but if there is a persistent rise in intracellular $\mathrm{Ca}^{2+}$ it will lead to disturbances in endoplasmic reticulum and mitochondrial $\mathrm{Ca}^{2+}$ homeostasis which results in neurodegenerative diseases ${ }^{14}$.

In $\mathrm{AD}$, amyloid beta induced neuronal cell death is associated with deregulation of $\mathrm{Ca}^{2+}$ dependent pathways ${ }^{15}$. In PD deregulation of intracellular $\mathrm{Ca}^{2+}$ lead to the selective destruction of dopaminergic neurons ${ }^{16}$. In HD mutant huntingtin releases $\mathrm{Ca}^{2+}$ from endoplasmic reticulum which results in neuronal death ${ }^{17}$.

\section{Oxidative stress-mediated neuronal damage}

Excessive production of reactive oxygen species (ROS) due to the imbalance of cellular biochemical process results in a condition known as oxidative stress ${ }^{18}$. ROS and reactive nitrogen species (RNS) mediated damage to cellular macromolecule is involved in the pathogenesis of neurodegenerative disease.

Neuronal degeneration and amyloid neurotoxicity in $\mathrm{AD}$ patients are associated with oxidative damage to DNA, RNA, proteins and lipids ${ }^{19}$. Oxidation of dopamine to a reactive 6-hydroxy dopamine results in the development of 
$\mathrm{PD}^{20}$. Oxidative stress induced mutations in the gene encoding for ubiquitous $\mathrm{Cu} / \mathrm{Zn}$ - superoxide dismutase (SOD-1) enzyme and damage to protein, lipid and DNA is associated with familial and sporadic forms of ALS ${ }^{21}$. Increased incidence of oxidative DNA strand breaks and exacerbated lipofucin, a pigment which is produced by the reaction of cellular amino compounds with aldehydic products of oxidative damage to the tissue macromolecule, is associated with $\mathrm{HD}^{22}$.

\section{Inflammation mediated neuronal damage}

Macrophages are present in the brain near glia and microglia and plays a fundamental role in inflammation-mediated neurodegenerative diseases. In disease state, the activated microglia mediate neuronal injury through the production of pro-inflammatory factors such as cytokines and chemokine ${ }^{23}$. Production of the cytokines and chemokines lead to the trans-endothelial migration of immune cells across the blood brain barrier.

There are several mechanisms identified for the microglia-mediated phagocytic and cytotoxic action which is responsible for neuronal damage. One of the major mechanisms is phagocytic oxidase mediated oxidative stress- induced neurotoxicity ${ }^{24}$. Inflammatory activation of phagocytic oxidase results in activation of microglia ${ }^{25}$ which in result in production of TNF- $\alpha$, IL-I $\beta$ and inducible NO synthase (iNOS). iNOS results in increased NO production leading to neuronal death.

\section{CURRENT THERAPY FOR NEURODEGENERATIVE DISEASES}

The drug treatment for neurodegenerative diseases is shown in the Table 1.

Though there are many pharmaceuticals available that improves the neuronal health, but the major disadvantage is that the chronic use of these pharmaceuticals is associated with multiple adverse effects as shown in Table 1. As a result nutraceutical are used over pharmaceuticals which are cost effective, beneficial and include lesser or no adverse effects. Hippocrates the father of medicine said that "let food be your medicine and medicine be your food" 26 . 
Table 1. Drugs used in various neurodegenerative disease along with their mechanism of actiond and adverse effects.

\begin{tabular}{|c|c|c|c|}
\hline $\begin{array}{l}\text { Neurodegenerative } \\
\text { Disease }\end{array}$ & Drug & Mechanism of Action & Adverse Effect \\
\hline $\begin{array}{l}\text { Amyotrophic lateral } \\
\text { sclerosis (ALS) }\end{array}$ & $\begin{array}{l}\text { Endaravone } \\
\text { (Radicava) }\end{array}$ & $\begin{array}{l}\text { Decreases the effect of } \\
\text { oxidative stress }\end{array}$ & $\begin{array}{l}\text { Hypersensitivity } \\
\text { reaction, respiratory } \\
\text { failure, eczema }\end{array}$ \\
\hline Parkinson's disease & $\begin{array}{l}\text { Levodopa/ } \\
\text { Carbidopa } \\
\text { (Sinemet) }\end{array}$ & $\begin{array}{l}\text { Levodopa-metabolic } \\
\text { precursor of dopamine, a } \\
\text { neurotransmitter depleted } \\
\text { in PD, crosses BBB and get } \\
\text { converted to dopamine by } \\
\text { striatal enzymes } \\
\text { Carbidopa-inhibit aromatic } \\
\text { amino acid decarboxylase } \\
\text { which in turn inhibit the } \\
\text { peripheral breakdown of } \\
\text { levodopa }\end{array}$ & $\begin{array}{l}\text { Edema, anxiety, } \\
\text { ataxia, dyskinesia, } \\
\text { confusion }\end{array}$ \\
\hline Alzheimer's disease & $\begin{array}{l}\text { Rivastigmine } \\
\text { (Exelon) }\end{array}$ & $\begin{array}{c}\text { Reversible acetyl- } \\
\text { cholinesterase inhibitor that } \\
\text { cause increase in concentration } \\
\text { of acetylcholine and enhances } \\
\text { cholinergic neurotransmission }\end{array}$ & $\begin{array}{c}\text { Tachycardia, seizure, } \\
\text { allergic dermatitis, } \\
\text { anorexia, headache, } \\
\text { dizziness }\end{array}$ \\
\hline $\begin{array}{l}\text { Huntington's } \\
\text { disease }\end{array}$ & $\begin{array}{l}\text { Tetrabenazine } \\
\text { (Xenazine) }\end{array}$ & $\begin{array}{l}\text { Reversibly inhibit vesicular } \\
\text { monoamine transporter type } \\
2 \text { resulting in decrease uptake } \\
\text { of monoamine into synaptic } \\
\text { vesicles and depletion of } \\
\text { monoamine stores from nerve } \\
\text { terminal }\end{array}$ & $\begin{array}{l}\text { Sedation, fatigue, } \\
\text { insomnia, depression, } \\
\text { extrapyramidal } \\
\text { events, anxiety, } \\
\text { nausea }\end{array}$ \\
\hline
\end{tabular}




\section{NUTRACEUTICALS}

Nutraceuticals is a term coined in 1979 by Stephen De Fliece ${ }^{27}$. It is a term combining the word nutrition (a nourishing food or a food component) and pharmaceutical (a medical drug) as shown in Figure 3.

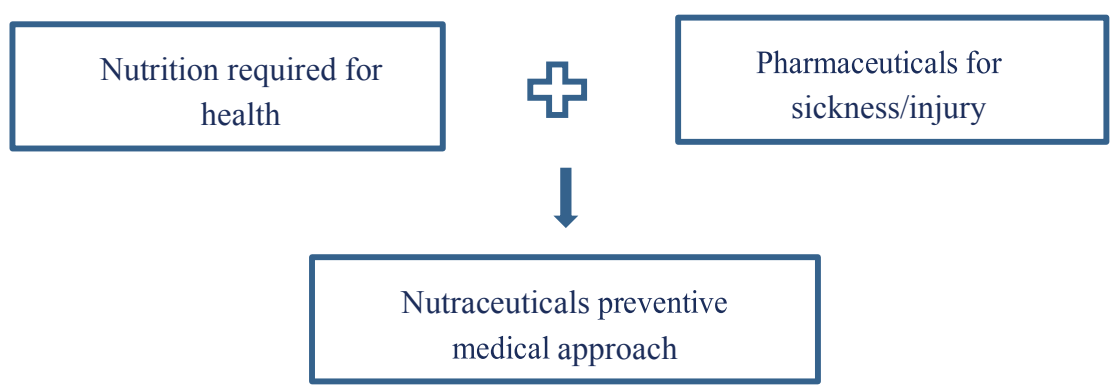

Figure 3. Concept of Nutraceuticals

Nutraceuticals is defined as a food or a part of food that provide medical or health benefit including the prevention and treatment of disease ${ }^{28}$.

Food and nutrient play an important role in the normal functioning of body. They are helpful in maintaining the health and reducing the risk of various disease. They are medicinal foods that play a role in maintaining wellbeing, enhancing health, modulating immunity and thereby preventing as well as treating specific diseases. Thus, the field of nutraceuticals are emerging as one of the missing block in the health benefit of an individual and it has been scientifically proven that nutraceutical are efficacious to treat and prevent various disease condition.

\section{BENEFITS OF NUTRACEUTICALS}

The major benefits of nutraceuticals include lesser or no adverse effects.

- They help us to avoid taking medications.

- They are economically affordable, easily available and has multiple therapeutic effect.

- They increase the health value by improving medical condition of the individuals.

- They act on multiple pathways linked to the neuronal cell death. 


\section{CLASSIFICATION OF NUTRACEUTICALS}

Nutraceuticals are classified on the basis of food source and chemical nature.

Nutraceuticals are classified into seven different types based on food source as shown in Figure 4.

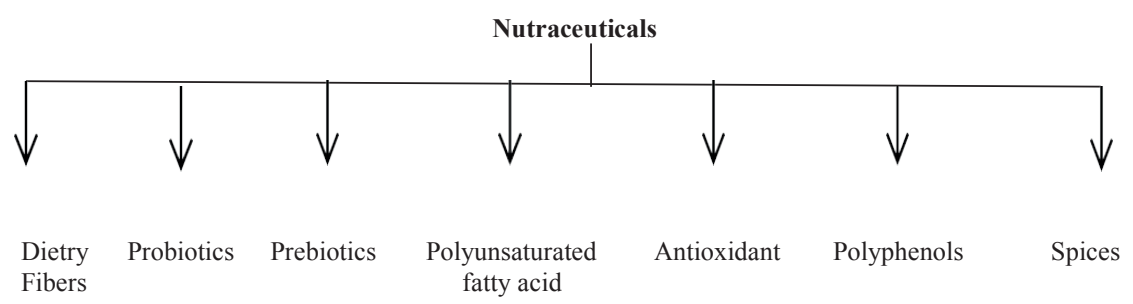

Figure 4. Classification of nutraceutical based on food source.

\section{Dietary fibers}

Plant origin substances present in food which are not digested and add bulk to the intestinal contents. Examples: Fruits, barley, oats, lignin, cellulose, pectin.

\section{Probiotics}

These are live microbial feed supplements which when administered in adequate dose, helps in improving the intestinal microbial balance of the host.

Examples: Lactobacilli, bifidobacilli, sacromyces cervicea.

\section{Prebiotics}

These are the dietry ingredients that benefit the host by selectively altering the composition or metabolism of gut microbial flora.

Examples: Chicory roots, banana, tomato and beans.

\section{Polyunsaturated fatty acids}

These may be,

Omega 3 fatty acids Examples: $\alpha$-linolenic acid, eicosapentaenoic acid, docosahexaenoic acid.

Omega 6 fatty acid Examples: arachidonic acid found in sunflower, soyabean and corn.

\section{Antioxidant}

These include vitamin $\mathrm{C}$, vitamin $\mathrm{E}$ and carotenoids. These vitamins are abun- 
dant in many fruits and vegetables and possess singlet oxygen quenching and lipid peroxidation preventing properties.

\section{Polyphenols}

These phytochemicals are produced by plant for protection against photosynthetic stress and reactive oxygen species. Examples: Flavonoids, anthocyanins and phenolic acids.

\section{Species}

These are food adjuncts used to enhance sensory quality of foods. Most of the components of spices are terpenes and essential oils.

\section{Classification of nutraceutical based on chemical nature}

Table 2 shows the classification of nutraceuticals based on their chemical nature.

Table 2. Classification of nutraceuticals based on chemical nature

\begin{tabular}{|l|l|l|}
\hline S. No & Class/component & Source \\
\hline 1 & Fatty acids & Milk and meat \\
\hline 2 & Omega-3 fatty acids (DHA, EPA) & Fish oils, maize, mustard and grape seed \\
\hline & $\begin{array}{l}\text { Polyphenols } \\
\text {-Anthocyanidine } \\
\text {-Catechins } \\
\text {-Flavonone } \\
\text {-Flavones } \\
\text {-Proanthocyanidine }\end{array}$ & $\begin{array}{l}\text { Fruits } \\
\text { Tea, mustard seed, grape seed } \\
\text { Citrus fruits } \\
\text { Fruits, vegetables, soyabean } \\
\text { Cocoa, chocolate, tea, grap }\end{array}$ \\
\hline 4 & Saponins & Soya bean, chick pea \\
\hline 5 & $\begin{array}{l}\text { Phytoestrogen } \\
\text {-Diadzein, Zenistein } \\
\text {-Lignans }\end{array}$ & $\begin{array}{l}\text { Soya bean, flax, lentil seed, maize } \\
\text { Flax, rye, vegetables }\end{array}$ \\
\hline \multirow{5}{*}{6} & $\begin{array}{l}\text { Carotenoids } \\
\text {-B-caroteine } \\
\text {-Luteine } \\
\text {-Zeoxanthine } \\
\text {-Lycopene }\end{array}$ & $\begin{array}{l}\text { Carrot, maize, oats } \\
\text { Fruits, vegetables } \\
\text { Eggs, citrus fruits, corn } \\
\text { Tomatoes }\end{array}$ \\
\hline 7 & $\begin{array}{l}\text { Isothiocyanate } \\
\text {-Sulforphane }\end{array}$ & Broccoli \\
\hline
\end{tabular}




\section{ROLE OF NUTRACEUTICAL IN NEURODEGENERATIVE DISEASES}

\section{Docosahexaenoic acid}

- It is an essential omega 3 polyunsaturated fatty acid that is found in marine fish. Mechanism of action:

- It produces anti-inflammatory effect by decreasing the production of pro inflammatory cytokines such as IL-1 $\beta$, IL- 6 and TNF- $\alpha$ and inhibits NF-k $\beta$ transcriptional activity.

- It decreases $\mathrm{A} \beta$ secretion from neuronal cells

- It is an important modulator for dopaminergic neuron in basal ganglion.

\section{Resveratrol}

- It is a polyphenolic phytoalexin, present in grapevines and legumes such as peanuts and tea. It exists in two geometric isomers, cis resveratol is unstable while trans resveratrol is biologically more active.

- It has a strong ability to remove free radicals due to the presence of $\mathrm{OH}$ group in position 3, 4 and 5 aromatic rings and a double bond in the molecule.

\section{Mechanism of action:}

- It reduces $\mathrm{A} \beta$ induced neuronal loss and memory impairment through reduction of iNOS expression.

- Acts as a free radical scavenger

- Increases 5-HT activity

\section{Epigallocatechin gallate}

- It is also known as epigallocatechin-3-gallate. It is the ester of epigallocatechin and gallic acid and is a type of catechin. It is mostly abundant in tea and also trace amount are fond in apple skin, plum, onion and hazel nut.

\section{Mechanism of action:}

- It has Iron chelation

- Act as free radical scavenger

- Modulates the ROS-NO pathway.

\section{Curcumin}

Curcumin is a diaryl hepatanoid polyphenol isolated from the rhizomes of Cur- 
cuma longa. It has multiple activities and it is effective against wide variety of diseases due to its anticarcinogenic, hepatoprotective, cardioprotective and neuroprotective properties.

\section{Mechanism of action:}

- It is a potent antioxidant because of its capacity to scavenge free radicals due to the presence of its unique structure which can donate $\mathrm{H}$ atoms or transfer electron from the phenolic sites.

- It also has anti-inflammatory activity as it inhibits lipopolysaccharide induced morphological changes of microglia and decreases the production of pro inflammatory factors.

- Restores glutathione levels which protect neurons against protein oxidation and preserves mitochondrial complex-I activity.

\section{Sulforphane}

Sulforphane is a compound within the isothiocyanate group of organosulfur compounds. It is obtained from cruciferous vegetables such as broccoli and cabbages.

\section{Mechanism of action:}

- In AD it increases acetylcholine levels and decreases acetylcholinesterase activity and also increases acetylcholine transferase expression in hippocampus and frontal cortex.

- It decreases ROS and inhibit pro inflammatory signaling through NF-k $\beta$.

\section{Anthocyanin}

- It is a polyphenol. Plants rich in anthocyanin include blueberry and raspberry. Mechanism of action:

- It negatively regulates pro inflammatory cytokines signaling pathway.

\section{Apigenin}

Apigenin is a flavonoid found in the flower of chamomile plants and also in celery, parsley and peppermint.

\section{Mechanism of action:}

It shows potent antioxidant antiapoptotic activity by protecting neuronal cells that are subjected to oxygen and glucose deprivation. 


\section{Coenzyme Q 10}

It is also known as ubiquonone. It is a coenzyme that is ubiquitous in animals and most bacteria.

\section{Mechanism of action:}

Potent antioxidant that can reduce oxidized form of $\alpha$-tocopherol to prevent lipid peroxidation.

Maintain proper transfer of the electrons in electron transport chain of mitochondria and ATP production.

a-lipoic acid

It is chemically synthesized, but also considered as a natural compound as it is a naturally occurring precursor of essential cofactors for mitochondrial enzymes including pyruvate dehydrogenase and $\alpha$-ketoglutarate dehydrogenase. It is a low molecular weight compound which easily crosses blood brain barrier (BBB). After crossing BBB, it is absorbed into the cells and reduced to dihydrolipoate acting as a potent antioxidant.

\section{Mechanism of action:}

- It increases acetylcholine production in $\mathrm{AD}$

- It inhibits the formation of hydroxyl radicals and ROS and increases the level of reduced glutathione.

- It can scavenge lipid peroxidation products.

\section{Vitamin C}

It is also known as ascorbic acid, is a water-soluble vitamin which is naturally present in some foods and also available as a dietary supplement. It is an important physiological antioxidant and has been shown to regenerate other antioxidants within the body.

\section{Mechanism of action:}

- Free radical scavenger in the cytosol ${ }^{29}$.

\section{Vitamin E}

Vitamin $\mathrm{E}$ is a fat-soluble vitamin that plays a role as an antioxidant in the body

\section{Mechanism of action:}

- It prevents lipid peroxidation. 


\section{Ginsenoside}

It is a phytoestrogen, which belongs to a class of molecules extracted from several species of ginseng

\section{Mechanism of action:}

- It maintains glutathione levels

- It prevents elevation of iron levels by regulating the expression of iron transport proteins.

\section{Genistein}

It is a phytoestrogen found mainly in soy and peanuts

\section{Mechanism of action:}

It increases the levels of malondialdehyde, superoxide dismutase and monoamine oxidase and exhibit antioxidant activity.

\section{CONCLUSION}

In recent years there is a growing interest in nutraceuticals which provide health benefits and are alternative to modern medicine. By using nutraceuticals, it may be possible to reduce or eliminate the need for conventional medications and reducing the chances of any adverse effects. Nutraceutical is demonstrated to have a physiological benefit and provide protection against neurodegenerative diseases.

\section{CONFLICT OF INTEREST}

There is no conflict of interest between the authors.

\section{REFERENCES}

1. Van, E. S. M. A.; Hardiman, O.; Chio, A.; AL-Chalabi, A.; Paterkamp, R. J.; Veldink, J. H.; Vnderberg, L. H. Amyotrophic lateral sclerosis. Lancet. 2017, 390, 2084-2098.

2. Hardiman, O.; AL-Chalabi, A.; Chio, A.; Corr, E. M.; Logoroscino, G.; Robberecht, W.; Shaw, P. J.; Simmon, S.; Van den berg, L. H. Amyotrophic lateral sclerosis. Nat. Rev. Dis. Prim. 2017, 3,17071 .

3. Tripathi, K. D. Antiparkinsonian Drugs. In Essentials of Medical Pharmacology. 7th ed. 2013, pp 425 .

4. Wang, J.; Gu, B. J.; Masters, C. L.; Wang, Y. J. A systemic view of Alzheimer disease-insight from amyloid beta metabolism beyond the brain. Nat Rev Neurol. 2017, 13, 612-623.

5 . Huntington disease information page: National institute of neurological disorder and stroke (NINDS) 2016. Archived from the original on 27, July. Retrived 19 July 2016.

6. Dayalu, P.; Albin, R. L. Huntington disease: pathogenesis and treatment. Neurol Clin. 2015, 33, 101-114. 
7. Raymond, A. C. Roos. Huntington disease: a clinical review. Roos Orphanet J Rare Dis. 2010, 3, 5-40.

8. Aliev, G.; Seyidova, D.; Neal, M. L.; Shi, J.; Lamb, B. T.; Siedlak, S. I.; Vinters, H. V.; Head, E.; Perry, G.; Lamanna, J. C.; Friedland, R. P.; Cotman C. W. Atherosclerotic lesions and mitochondria DNA deletions in brain micro vessels as a central target for the development of human $\mathrm{AD}$ and $\mathrm{AD}$-like pathology in aged transgenic mice. Ann. N. Y. Acad. Sci. 2002, 977, 45-46.

9. Beal, M. F. Mitochondria take center stage in aging and neurodegeneration. Ann. Neurol. 2005, 58, 247-254.

10. Nicklas, W. J.; Vyas, I.; Heikkilia, R. E. Inhibition of NADH-linked oxidation in brain mitochondria by 1-methyl-4- phenyl-pyridine, a metabolite of the neurotoxin, 1-methyl-4-phenyl-1, 1, 5, 6-teterhydropyridine. Life Sci. 1985, 36, 2503-2508.

11. Tang, T. S.; Slow, E.; Lupu, V.; Stavrovskaya, I. G.; Sugimori, M.; Llinas, R.; Kristal, B. S.; Hayden, M. R.; Bezprozvanny, I. Disturbed $\mathrm{Ca}^{2+}$ signaling and apoptosis of medium spiny neurons in huntington's disease. Proc. Natl. Acad. Sci. USA. 2005, 102, 2602-2607.

12. Gu, M.; Gash, M. T.; Mann, V. M.; Javoy-Agid, F.; Copper, J. M.; Schapira, A. H. Mitochondrial defect in huntington's disease caudate nucleus. Ann. Neurol. 1996, 39, 385-389.

13. Schalaepfer, W. W.; Bunge, R. P. Effects of calcium ion concentration on the degeneration of amputated axons in tissue culture. J. Cell. Biol. 1973, 59, 456-470.

14. Celsi, F.; Pizzo, P.; Brini, M.; Leo, S.; Fotino, C.; Pinton, P.; Rizzuto, R. Mitochondria, calcium and cell death: a deadly triad in neurodegeneration. Biochim. Biophys Acta. 2009, 1787, $335-344$.

15. Zündorf, G.; Reiser, G. Calcium dysregulation and homeostasis of neural calcium in the molecular mechanisms of neurodegenerative diseases provide multiple targets for neuroprotection. Antioxid. Redox. Signal. 2011, 14, 1275- 1288.

16. Chan, C. S.; Gertler, T. S.; Surmeier, D. J. Calcium homeostasis, selective vulnerability and Parkinson's disease. Trends Neurosci. 2009, 32, 249-256.

17. Lim, D.; Fedrizzi, L.; Tartari, M.; Zuccato, C.; Cattaneo, E.; Brini, M.; Carafoli, E. Calcium homeostasis and mitochondrial dysfunction in striatal neurons of Huntington disease. J. Biol. Chem. 2008, 283, 5780-5789.

18. Betteridge, D. J. What is oxidative stress? Metabolism. 2000, 49, Suppl. 1, 3-8.

19. Hensley, K.; Butterfield, D. A.; Hall, N.; Cole, P., Subramaniam, R.; Mark, R.; Mattson, M. P.; Markesbery, W. R.; Harris, M. E.; Aksenov, M. Reactive oxygen species as causal agents in the neurotoxicity of the Alzheimer's disease- associated amyloid beta peptide. Ann. N. Y. Acad Sci. 1996, 786, 120-134.

20. Napolitano, A.; Crescenzi, O.; Pezzella, A.; Prota, G. Generation of the neurotoxin 6-hydroxydopamine by peroxidase $/ \mathrm{H}_{2} \mathrm{O}_{2}$ oxidation of dopamine. J. Med. Chem. 1995, 38, 917-922.

21. Pedersen, W. A.; Fu, W.; Keller, J. N.; Markesbery, W. R.; Appel, S.; Smith, R. G.; Kasarskis, E.; Mattson, M. P. Protein modification by the lipid peroxidation product 4-hydroxynonenal in the spinal cords of amyotrophic lateral sclerosis patients. Ann. Neurol. 1998, 44, 819-824.

22. Goebel, H. H.; Heipertz, R.; Scholz, W.; Iqbal, K.; Tellez-Nagel, I. Juvenile Huntington chorea: clinical, ultrastructural, and biochemical studies. Neurol. 1978, 28, 23-31.

23. Gendelman, H. E. Neural immunity: Friend or foe? J. Neurovirol. 2002, 8, 474-479.

24. Bal-Price, A.; Matthias, A.; Brown, G. C. Stimulation of the NADPH oxidase in activated rat microglia removes nitric oxide but induces peroxynitrite production. $J$. Neurochem. 2002, 80 , 
73-80.

25. Mander, P. K.; Jekabsone, A.; Brown, G. C. Microglia proliferation is regulated by hydrogen peroxide from NADPH oxidase. J. Immunol. 2006, 176, 1046-1052.

26. Biesalaki, H. K. Nutraceuticals: the link between nutrition and medicine. In: Kramer, K.; Hoppe, P. P.; Packer, L.; editors. Nutraceuticals in health and disease prevention. New York, Marcel Dekker Inc. 2001, pp 1-26.

27. Defeliece, S. L. Nutrceuticals: Oppurtunities in Emerging Market. Scrip Mag. 1992, 9.

28. Defelice, S. L. The Nutraceutical Revolution - Its Impact on Food Industry R\&D. Trends Food Sci. Tech. 1995, 6, 59-61.

29. Garima, V.; Manoj, K. M. A review on nutraceuticals: classification and its role in various diseases. Inter J. Pharm. Thera. 2016, 7, 152-160. 